\title{
Vibrations induced by HST passage on ballast and non-ballast tracks
}

\author{
P. Galvín, A. Romero, J. Domínguez \\ Escuela Técnica Superior de Ingenieros, Universidad de Sevilla, Camino de los Descubrimientos, 41092 Sevilla, Spain
}

\begin{abstract}
The use of ballastless slab track is significantly increasing in HST line technology. This development is due to some structural and operational advantages over ballasted track. In addition, floating slab tracks can be used to control ground-borne vibrations generated by surface and underground rail transportation systems. In this paper, a general and fully three dimensional multi-body-finite element-boundary element model is used to study vibrations due to train passage on ballast and non-ballast tracks. The vehicle is modelled as a multi-body system, the track, in both cases, using finite elements and the soil is represented using boundary elements. The three components of the load are considered; the quasi-static excitation (force generated by moving axle loads), the parametric excitation due to discrete supports of the rails and the excitation due to wheel and rail roughness and track unevenness. Track receptances are computed for both track systems and vibrations induced by high-speed train passage at the track and the free-field are evaluated for different train speeds. Soil behaviour changes significantly with the track system. Finally, a floating slab track is studied to show how this type of solution leads to a significant vibration reduction for surface tracks.
\end{abstract}

Key words: Slab track, HST vibrations, vehicle-track-soil-structure interaction, dynamic loads

\section{Introduction}

New slab track installations are being developed in Europe and Asia in order to come across a track for high-speed passenger and heavy-load freight service lines that will operate with low maintenance costs. This innovative concrete slab could replace the classical ballast track $\underline{[1]}$. Up to now, slab tracks have been installed in tunnels and structures where low maintenance is desired. However, all new high-speed lines (HSL) in Japan are being built on slab track support systems. In Europe, the new HSL-Zuid will be built using a slab track system on piles, due to the high softness and permeability of the soils. In Spain, the use of slab track is also being considered for new lines.

Environmental problems related to vibrations induced by train passage are being studied while a rapid development of HSL takes place. Malfunctioning of sensitive equipment and passenger discomfort are recognized as the main negative consequences of vibration from railway traffic. The limit for human perception of

\footnotetext{
Email address: pedrogalvin@us.es (P. Galvín)

Preprint submitted to Soil Dynamics and Earthquake Engineering
}

March 2, 2010 
vibration is $0.2 \mathrm{~mm} / \mathrm{s}$ [2]. This limit which can be easily exceeded not only aboard of the train but in areas with railway traffic. The dynamic behaviour of vehicle, track, soil and structure systems must be studied and so it has been in the past, leading to the conclusion that dynamic effects are much more important for high-speed trains (HST) than for conventional trains [3]. The main reason is that HST may operate close to the critical speed. This critical speed for trains on ballast track is close to the minimum velocity of the Rayleigh waves in the subsoil $\underline{44}, 5, \underline{6}, \underline{7]}$. However, the vehicle-track-soil behaviour in non-ballasted tracks, such as slab tracks, can be different. The problem requires deep analysis in order to ensure security and comfort in trains and to avoid problems due to vibrations induced in nearby constructions. Moreover, slab tracks may allow an easier control of ground-borne vibration than ballast tracks by using floating slab track systems. Floating slab tracks have been successfully used as an effective system for reducing vibrations in underground and surface lines $[8, \underline{9,} \underline{10]}$.

One of the first steps on the study of vibrations induced by HST is an accurate modelling of the force induced by the train which is transmitted to the soil through the track. This force is generated by a variety of excitation mechanisms: a quasi-static contribution, a parametric excitation due to the existence of discrete supports of the rails, a transient excitation due to the rail joints and wheel flats, and the excitation due to wheel and rail roughness and track unevenness $\underline{11]}$. In early studies, a prediction load model developed by Krylov $\underline{[12]}$ was used $\underline{[13,14]}$. In that model, only the quasi-static force transmitted by the sleepers in a ballasted track was taken into account. Krylov's model is valid when the train speed is close to the critical phase velocity of the coupled track-soil system. In that case, the quasi-static excitation is dominant $[15,16,17]$. The contribution of other components of the load is significant for other values of the train speed.

In recent years, more sophisticated models have been used allowing the dynamic train-track interaction

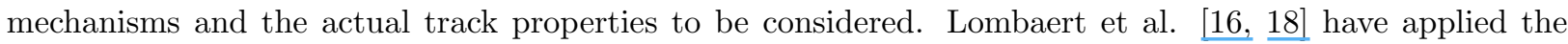
formulation presented by Metrikine et al. [19], Metrikine and Popp [20], and Dieterman and Metrikine $\underline{[4]}$, to predict vibrations produced by railway traffic using a coupled two-and-half boundary element-finite element formulation in the frequency domain. In that approach the vehicle is coupled to a beam of infinite length that represents the track and a half-space representing the soil. The model has been validated with

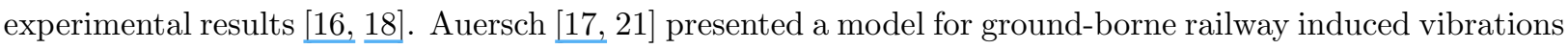
formulated in a similar way. Takemiya and Bian $\underline{[22]}$ extended the model presented by Metrikine and Popp $\underline{23]}$ to consider the facts that rails are based discretely on the ground and that sleepers have a significant inertia effect on the rails. They included a layered soil in the analysis and used a discrete Kelvin model

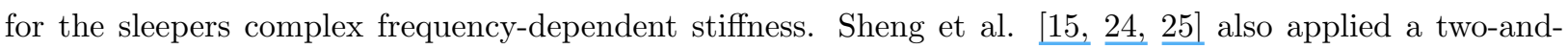
a-half-dimensional frequency domain model to study vibrations due to train passage. In that model, the dynamic train-track interaction is taken into account using an infinite layered beam for the track coupled to a layered half-space. Those numerical models are formulated in a two-and-a-half domain, and vehicle-track 
interaction and track-soil interaction are decoupled using, for example, the Green's functions for a layered half-space $[26,27]$. Therefore, it is supposed that the ground and structures such as tunnels and tracks, are homogeneous in the track direction. In this context, Xia et al. [7] have recently presented an integrated train-track-subsoil dynamic interaction model for moving-train induced ground vibration based on vehicle dynamics, track dynamics and the Green's functions of the soil.

The literature review shows that the railway engineering community have conducted many researches related to induced vibrations by HST passage on ballast tracks in recent years; however, the dynamic behaviour of non-ballast tracks has not been analysed that much and requires deeper investigation. The objective of the present paper is to compute the vibration at the track and free-field induced by HST passage on ballast and no ballast tracks using a general and fully coupled three dimensional multi-body-finite element-boundary element model. Both, the influence of quasi-static and dynamic excitation mechanisms in relation to train speed, and the value of the critical speed as compared to the actual train speed, are analysed for different track configurations. The numerical analysis is formulated in the time domain. The vehicle is modelled as a multi-body system and, therefore, the quasi-static and the dynamic excitation mechanisms can be considered. Track is modelled using finite elements considering the non-linear behaviour within the time domain [28]. The soil is represented using the boundary element method [29, 30], in combination with a full-space fundamental solution [31]. Internal material damping is introduced in the boundary element time domain formulation in a simple and efficient manner $\underline{\underline{[14}}, \underline{32}, \underline{33]}$.

The outline of the paper is as follows. First, the numerical model is presented. This presentation includes: a brief summary of the finite element and the boundary element time domain formulations, the multibody model used to represent the train-track-soil dynamic interaction, and the quasi-static and dynamic load components. The dynamic load is due to the discrete supports of the rails, and to rails and wheels irregularities. Second, the track receptance of a ballast track, a slab track and a floating slab track are computed and analyzed. Finally, vibrations induced by HST passage are computed for different tracks and different train speeds. The influence of the quasi-static and dynamic excitation mechanisms in relation to the train speed and soil dynamic properties, is analyzed.

\section{Numerical model}

The model is based on three-dimensional finite element $[28]$ and boundary element $[29,30,31]$ time domain formulations. A multi-body model is considered to represent the vehicle and the quasi-static and dynamic load components transmitted by the train to the soil through the track.

\subsection{Boundary Element Formulation}

The boundary element method system of equations can be solved step-by-step to obtain the time variation of the boundary unknowns; i.e. displacements and tractions. Piecewise constant time interpolation 
functions are used for tractions and piecewise linear functions for displacements. The displacement and traction fundamental solution are evaluated analytically without much difficulty, and nine node rectangular and six node triangular quadratic elements are used for spatial discretization. Explicit expressions of the fundamental solution displacements and tractions corresponding to an impulse point load in a three dimensional elastic full-space can be seen in Ref. [32]. An approach based on the idea of using a linear combination of equations for several time steps in order to advance one step is used to ensure that the stepping procedure is stable in time [34]. Finally, an approach based on the classical Barkan expression [35] is employed to account for material damping in the soil. Once the integral equation is discretized one obtains the following equation for each time step:

$$
\mathbf{H}^{n n} \mathbf{u}^{n}=\mathbf{G}^{n n} \mathbf{p}^{n}+\sum_{m=1}^{n-1}\left(\mathbf{G}^{n m} \mathbf{p}^{m}-\mathbf{H}^{n m} \mathbf{u}^{m}\right) \exp [-2 \pi \alpha(n-m) \Delta t]
$$

where, $\mathbf{u}^{n}$ is the displacement vector, $\mathbf{p}^{n}$ is the traction vector, $\mathbf{H}^{n n}$ and $\mathbf{G}^{n n}$ are the fully unsymmetrical boundary element system matrices in the time interval $n, \alpha$ is the soil attenuation coefficient and $\Delta t$ is the time step. The right hand side term derived from previous steps is damped by an exponential coefficient with an exponent that linearly increases with time.

\subsection{Finite Element Formulation}

If an implicit time integration Newmark's method is applied [36] the equation, which results from the finite element method, can be expressed symbolically as follows :

$$
\mathbf{D}^{n n} \mathbf{u}^{n}=\mathbf{f}^{n}+\mathbf{f}^{n-1}
$$

where $\mathbf{D}^{n n}$ is the dynamic stiffness matrix, $\mathbf{u}^{n}$ the displacement vector and $\mathbf{f}^{n}$ the equivalent force vector, in the time interval $n$. Spring-damper, beam, shell and solid elements are used for the discretization.

\subsection{Vehicle model}

The multi-body model shown in Fig. 1 is used to represent the train-track dynamic interaction due to an axle passage. The articulated HST studied in this paper have two traction cars and eight passenger cars. The two passenger cars adjacent to the traction cars share one bogie with the neighbouring passenger car, while the six central passenger cars share both bogies with the neighbouring cars. The primary and secondary suspensions isolate the carriages from the track vibrations. The axles and the car body are considered as rigid parts and the primary and secondary suspensions are represented by spring and damper elements $[24,37]$. The coupling between axles on the same bogie, known as leakage, is ignored. 


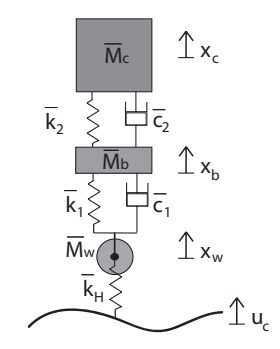

Figure 1: The multi-body model for an axle.

The axle equations of motion can be written as follows:

$$
\begin{gathered}
{\left[\begin{array}{cccc}
\bar{M}_{c} & 0 & 0 & 0 \\
0 & \bar{M}_{b} & 0 & 0 \\
0 & 0 & \bar{M}_{w} & 0 \\
0 & 0 & 0 & 0
\end{array}\right]\left[\begin{array}{c}
\ddot{x}_{c} \\
\ddot{x}_{b} \\
\ddot{x}_{w} \\
\ddot{u}_{c}
\end{array}\right]+\left[\begin{array}{cccc}
\bar{c}_{2} & -\bar{c}_{2} & 0 & 0 \\
-\bar{c}_{2} & \bar{c}_{1}+\bar{c}_{2} & -\bar{c}_{1} & 0 \\
0 & -\bar{c}_{1} & \bar{c}_{1} & 0 \\
0 & 0 & 0 & 0
\end{array}\right]\left[\begin{array}{c}
\dot{x}_{c} \\
\dot{x}_{b} \\
\dot{x}_{w} \\
\dot{u}_{c}
\end{array}\right]+} \\
{\left[\begin{array}{cccc}
\bar{k}_{2} & -\bar{k}_{2} & 0 & 0 \\
-\bar{k}_{2} & \bar{k}_{1}+\bar{k}_{2} & -\bar{k}_{1} & 0 \\
0 & -\bar{k}_{1} & \bar{k}_{1}+\bar{k}_{H} & -\bar{k}_{H} \\
0 & 0 & -\bar{k}_{H} & \bar{k}_{H}
\end{array}\right]\left[\begin{array}{c}
x_{c} \\
x_{b} \\
x_{w} \\
u_{c}
\end{array}\right]=\left[\begin{array}{c}
\bar{M}_{b} \\
\bar{M}_{a} \\
\bar{M}_{w} \\
0
\end{array}\right] \mathbf{g}+\left[\begin{array}{c}
0 \\
0 \\
0 \\
F_{c}
\end{array}\right]}
\end{gathered}
$$

where $x_{c}, x_{b}$ and $x_{w}$ represent the car body, bogie and wheel displacements, respectively. $\mathrm{g}$ is the acceleration of gravity. The load transmitted by an axle depends on the car body mass, $M_{c}$, the bogie mass, $M_{b}$, the mass of the wheels, $M_{w}$, the primary suspension, $k_{1}$ and $c_{1}$, the secondary suspension, $k_{2}$ and $c_{2}$, and the train configuration. The bogies are supported by four wheels, therefore, a wheel transmits a quarter of the total bogie mass, $\left(\bar{M}_{b}=M_{b} / 4\right)$. The primary suspension connects the wheels to the bogie, therefore, $\bar{k}_{1}$ and $\bar{c}_{1}$ represents the total primary vertical stiffness and the total primary vertical viscous damping, respectively. In a traction car, the car body is supported by two bogies (eight wheels) and every wheel transmits an eighth of the car body $\left(M_{c}=\bar{M}_{c} / 8\right)$. The secondary suspension connects the bogie centre to the car body. The car body mass transmitted by a wheel is isolated by a quarter of the secondary suspension. Then, $\bar{k}_{2}$ and $\bar{c}_{2}$ represent a quarter of the secondary vertical stiffness and secondary vertical viscous damping, respectively. Similar models can be derived for the passenger cars, taking into account the fact that adjacent cars are coupled by shared bogies. $u_{c}$ denotes the total displacement of the rail and $F_{c}$ the contact force between the wheel and the rail. Wheel-rail coupling is illustrated in Fig. 1, where a Hertzian contact spring is inserted between both elements $\underline{[1,} \underline{24}]$. The stiffness of this Hertzian contact spring is denoted by $\bar{k}_{H}$ and its value is taken from $\underline{[1]}$.

The displacement vector $u_{c}$ is equal to the sum of the actual rail displacement $u_{r}$ and the rail unevenness 
$u_{w / r}$ perceived by an axle when a perfect contact is assumed $[16, \underline{18]}$ :

$$
u_{c}=u_{r}+u_{w / r}
$$

In this paper, the artificial track profile $u_{w / r}$ is generated from PSD according to ISO 8608 [38]. Details of this methodology can be found in $[16, \underline{18}]$.

\subsection{Multi-body-Finite element-Boundary element coupling}

The boundary element Eq. 1 can be split in two parts, one for the nodes on the interface with the finite element sub-region and another for the nodes that are not shared with any other sub-region. Subindex $c$ indicates the number of degrees of freedom associated with the interface and sub-index $b$ those corresponding to other boundary elements. The forces at all boundary element nodes are computed from their corresponding nodal tractions. Thus Eq. 1 can be rewritten as follows:

$$
\begin{aligned}
& {\left[\begin{array}{ll}
\mathbf{H}_{c c}^{n n} & \mathbf{H}_{c b}^{n n} \\
\mathbf{H}_{b c}^{n n} & \mathbf{H}_{b b}^{n n}
\end{array}\right]\left[\begin{array}{c}
\mathbf{u}_{c}^{n} \\
\mathbf{u}_{b}^{n}
\end{array}\right]=\left[\begin{array}{ll}
\widehat{\mathbf{G}}_{c c}^{n n} & \widehat{\mathbf{G}}_{c b}^{n n} \\
\widehat{\mathbf{G}}_{b c}^{n n} & \widehat{\mathbf{G}}_{b b}^{n n}
\end{array}\right]\left[\begin{array}{c}
\mathbf{f}_{c}^{n} \\
\mathbf{f}_{b}^{n}
\end{array}\right]+} \\
& \sum_{m=1}^{n-1}\left(\left[\begin{array}{cc}
\widehat{\mathbf{G}}_{c c}^{n m} & \widehat{\mathbf{G}}_{c b}^{n m} \\
\widehat{\mathbf{G}}_{b c}^{n m} & \widehat{\mathbf{G}}_{b b}^{n m}
\end{array}\right]\left[\begin{array}{c}
\mathbf{f}_{c}^{m} \\
\mathbf{f}_{b}^{m}
\end{array}\right]-\left[\begin{array}{cc}
\mathbf{H}_{c c}^{n m} & \mathbf{H}_{c b}^{n m} \\
\mathbf{H}_{b c}^{n m} & \mathbf{H}_{b b}^{n m}
\end{array}\right]\left[\begin{array}{l}
\mathbf{u}_{c}^{m} \\
\mathbf{u}_{b}^{m}
\end{array}\right]\right) \exp [-2 \pi \alpha(n-m) \Delta t]
\end{aligned}
$$

where:

$$
\mathbf{f}=\left[\sum_{a=1}^{A} \int_{\Gamma} \mathbf{N}^{T} \mathbf{N} d \Gamma\right] \mathbf{p}=\mathbf{L} \mathbf{p} \quad \text { and } \quad \hat{\mathbf{G}}=\mathbf{G L}^{-1}
$$

being $\mathbf{N}$ the shape functions vector. Summation extends over the elements $A$ that contain the corresponding boundary element node.

The finite element Eq. 2 can also be split as follows,

$$
\left[\begin{array}{ll}
\mathbf{D}_{c c}^{n n} & \mathbf{D}_{c f}^{n n} \\
\mathbf{D}_{f c}^{n n} & \mathbf{D}_{f f}^{n n}
\end{array}\right]\left[\begin{array}{c}
\mathbf{u}_{c}^{n} \\
\mathbf{u}_{f}^{n}
\end{array}\right]=\left[\begin{array}{c}
\mathbf{f}_{c}^{n} \\
\mathbf{f}_{f}^{n}
\end{array}\right]+\left[\begin{array}{c}
\mathbf{f}_{c}^{n-1} \\
\mathbf{f}_{f}^{n-1}
\end{array}\right]
$$

where sub-index $c$ indicates the degrees of freedom within the boundary element sub-region and $f$ stands for the rest of the finite elements degrees of freedom.

Coupling boundary element and finite element sub-regions entails satisfying equilibrium and compatibility conditions at the interface between both regions. To do so, different approaches may be employed [29, 30]. In this paper, domain formulations in time are coupled directly by writing boundary element equations and finite element equations in a single global system together with the equilibrium and compatibility equations 
[39]. Thus,

$$
\begin{gathered}
{\left[\begin{array}{cccc}
\mathbf{H}_{c c}^{n n} & \mathbf{H}_{c b}^{n n} & -\widehat{\mathbf{G}}_{c c}^{n n} & \mathbf{0} \\
\mathbf{H}_{b c}^{n n} & \mathbf{H}_{b b}^{n n} & -\widehat{\mathbf{G}}_{b c}^{n n} & \mathbf{0} \\
\mathbf{D}_{c c} & \mathbf{0} & -\mathbf{I} & \mathbf{D}_{c f} \\
\mathbf{D}_{f c} & \mathbf{0} & \mathbf{0} & \mathbf{D}_{f f}
\end{array}\right]\left[\begin{array}{c}
\mathbf{u}_{c}^{n} \\
\mathbf{u}_{b}^{n} \\
\mathbf{f}_{c}^{n} \\
\mathbf{u}_{f}^{n}
\end{array}\right]=\left[\begin{array}{c}
\widehat{\mathbf{G}}_{c b}^{n n} \mathbf{f}_{b}^{n} \\
\widehat{\mathbf{G}}_{b b}^{n n} \mathbf{f}_{b}^{n} \\
\mathbf{0} \\
\mathbf{f}_{f}^{n}
\end{array}\right]+} \\
{\left[\begin{array}{c}
\sum_{m=1}^{n-1}\left(\widehat{\mathbf{G}}_{c c}^{n m} \mathbf{f}_{c}^{m}+\widehat{\mathbf{G}}_{c b}^{n m} \mathbf{f}_{b}^{m}-\mathbf{H}_{c c}^{n m} \mathbf{u}_{c}^{m}-\mathbf{H}_{c b}^{n m} \mathbf{u}_{b}^{m}\right) \exp [-2 \pi \alpha(n-m) \Delta t] \\
\sum_{m=1}^{n-1}\left(\widehat{\mathbf{G}}_{b c}^{n m} \mathbf{f}_{c}^{m}+\widehat{\mathbf{G}}_{b b}^{n m} \mathbf{f}_{b}^{m}-\mathbf{H}_{b c}^{n m} \mathbf{u}_{c}^{m}-\mathbf{H}_{b b}^{n m} \mathbf{u}_{b}^{m}\right) \exp [-2 \pi \alpha(n-m) \Delta t] \\
\mathbf{f}_{c}^{n-1} \\
\mathbf{f}_{f}^{n-1}
\end{array}\right]}
\end{gathered}
$$

This system of equations is used in the present model to represent the track and the structures (finite elements) and the soil (boundary elements).

Eq. 3 is introduced into the boundary element-finite element system of equations (Eq. 8) taking into account compatibility of displacements and equilibrium of forces at the wheel-rail contact point. Thus, the vehicle-track interaction forces, considering the train-track-soil dynamic interaction, can be taken into account in the problem and evaluated if required.

As the vehicle circulates along the track at a particular speed, the contact point between the vehicle and the rail changes (Fig. 2). A moving node is created in the rail to couple the vehicle and the track. So the track mesh including the rail changes at each time step and the obtained finite element system of equations becomes non-linear because mass, damping and stiffness matrices vary at each time step. Nevertheless, the time domain formulation allows to solve the obtained non-linear system of equations using the methodology presented in Ref. [40].

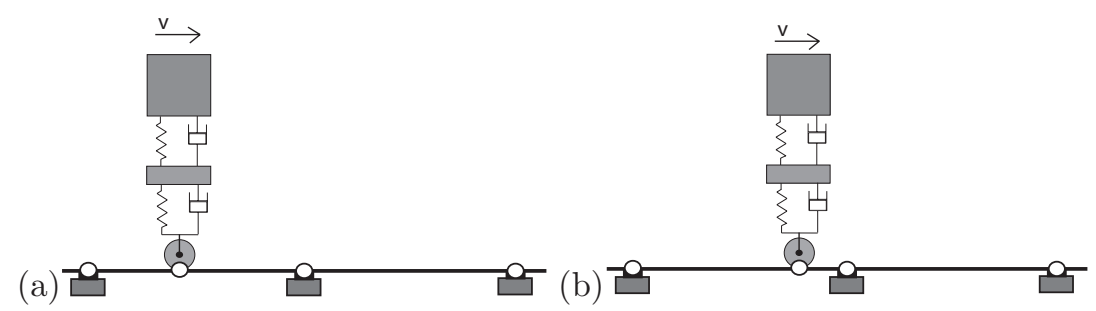

Figure 2: Vehicle and track model at: (a) time step $n$ and (b) time step $n+1$.

\section{The track dynamic response}

The track receptance is computed as a function of the frequency for three different track systems: ballasted track, slab track and floating slab track. To this end, the systems are subjected to a series of unit amplitude sinusoidal excitations applied at both rails at the centre line of the mesh. The response time 
history is computed using the discretizations show in Fig. 3. The meshes have a total length of $86 \mathrm{~m}$ and a width of $29 \mathrm{~m}$. They are long enough to properly represent the effect of a load travelling from far away [32]. The frequency content of the response is used to define the receptance.

All the track systems considered in this paper are composed of two UIC60 rails with a bending stiffness $E_{r} I_{r}=6.45 \times 10^{6} \mathrm{Nm}^{2}$ and a mass per unit length $m_{r}=60.3 \mathrm{~kg} / \mathrm{m}$ for each rail. The rail-pads are 10 mm thick and their stiffness and damping values are $k_{r p}=150 \times 10^{6} \mathrm{~N} / \mathrm{m}$ and $c_{r p}=13.5 \times 10^{3} \mathrm{Ns} / \mathrm{m}$, respectively. The prestressed concrete monoblock sleepers have a length $l_{s l}=2.60 \mathrm{~m}$, a width $w_{s l}=0.235$ $\mathrm{m}$, a height $h_{s l}=0.205 \mathrm{~m}$ (under the rail) and a mass $m_{s l}=300 \mathrm{~kg}$. A distance $d_{s l}=0.6 \mathrm{~m}$ between sleepers is considered. The rails and the sleepers are modelled as Bernoulli-Euler beam elements and the rail-pads are modelled as spring-damper elements.

(a)

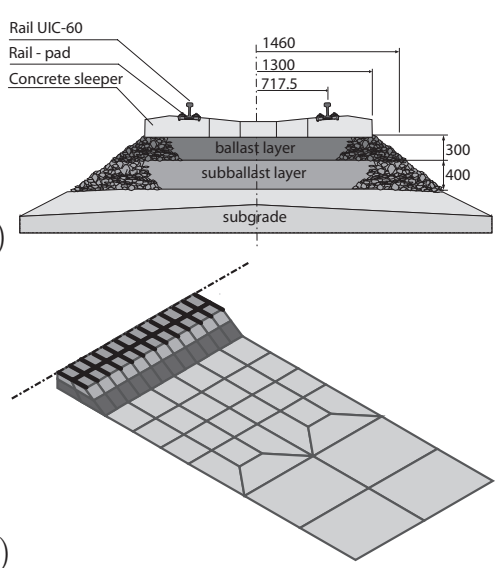

(b)

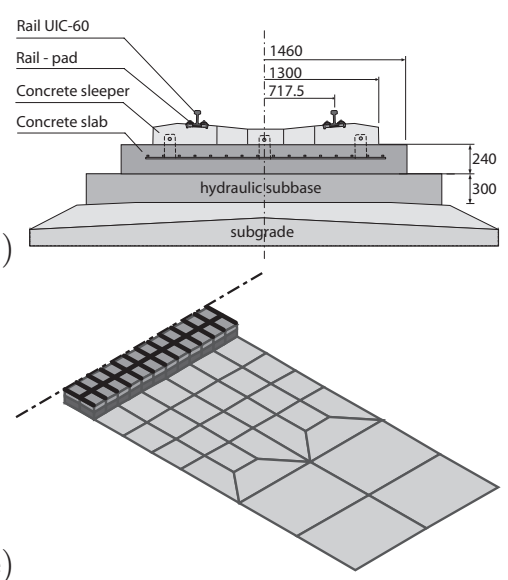

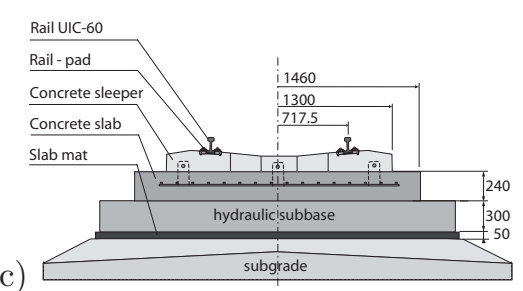

(f)

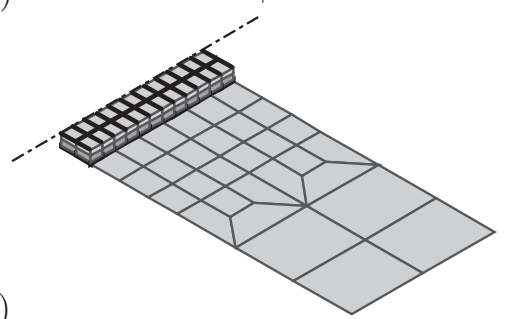

Figure 3: Cross section and discretization detail for: (a-d) ballast track, (b-e) slab track and (c-f) floating slab track.

Fig. 3. (a) shows a classical ballast track. The resilience of the track is due to two layers: a ballast layer on a subballast layer. The ballast has a Young's modulus $E_{b}=280 \times 10^{6} \mathrm{~N} / \mathrm{m}^{2}$, a shear modulus $G_{b}=116 \times 10^{6}$ $\mathrm{N} / \mathrm{m}^{2}$ and a density $\rho_{b}=1500 \mathrm{~kg} / \mathrm{m}^{3}$. The subballast layer has a Young's modulus $E_{s b}=140 \times 10^{6} \mathrm{~N} / \mathrm{m}^{2}$, a shear modulus $G_{s b}=58 \times 10^{6} \mathrm{~N} / \mathrm{m}^{2}$ and a density $\rho_{s b}=1500 \mathrm{~kg} / \mathrm{m}^{3}$. The damping value in both layers is $c_{b}=24 \times 10^{3} \mathrm{Ns} / \mathrm{m}^{2}$. The width of the ballast equals $2.92 \mathrm{~m}$ and the height $h_{b}=0.7 \mathrm{~m}$. The ballast and the subballast layers are represented by solid elements.

The slab track system is composed of a concrete slab on a hydraulic subbase (Fig. 3.(b)). The concrete slab has a Young's modulus $E_{s}=34 \times 10^{9} \mathrm{~N} / \mathrm{m}^{2}$, a shear modulus $G_{s}=14.2 \times 10^{9} \mathrm{~N} / \mathrm{m}^{2}$ and a density $\rho_{s}=2500 \mathrm{~kg} / \mathrm{m}^{3}$. The hydraulic subbase has a Young's modulus $E_{h s}=10 \times 10^{9} \mathrm{~N} / \mathrm{m}^{2}$, a shear modulus $G_{h s}=4.2 \times 10^{9} \mathrm{~N} / \mathrm{m}^{2}$, a density $\rho_{h s}=2500 \mathrm{~kg} / \mathrm{m}^{3}$ and the same width as the concrete slab. The slab and the subbase are represented by solid elements.

In the case of the floating slab track, a slab mat is considered under the slab (Fig. 3.(c)). The slab 
mat has a Young's modulus $E_{f}=0.5 \times 10^{6} \mathrm{~N} / \mathrm{m}^{2}$, a density $\rho_{f}=100 \mathrm{~kg} / \mathrm{m}^{3}$ and a damping value equals $c_{f}=87.6 \times 10^{3} \mathrm{Ns} / \mathrm{m}^{2}$. The slab mat is represented by solid elements. For a floating slab track, the isolation frequency is defined as the resonance frequency of a single-degree-of-freedom system with a mass equal to the slab's mass per unit length and stiffness equal to the vertical stiffness of the slab bearings:

$$
f=\frac{1}{2 \pi} \sqrt{\frac{k_{f}}{m_{s}}}
$$

In this case, if $m_{s}$ is the mass of the concrete slab and the hydraulic subbase, the isolation frequency equals $13.69 \mathrm{~Hz}$.

The tracks are located at the surface of a homogeneous half-space that represents a soft soil, with a S-wave velocity $c_{s}=80 \mathrm{~m} / \mathrm{s}$, a P-wave velocity $c_{p}=150 \mathrm{~m} / \mathrm{s}$, and a Rayleigh wave velocity $c_{R}=74 \mathrm{~m} / \mathrm{s}$. These soil properties coincide with those obtained for the upper soil layer from experimental measurements in the HSL between Brussels and Paris [13]. The soil attenuation coefficient $\alpha$ equals 4 . The S-wave velocity in the soil is closed to the train speed, therefore, the critical speed for trains on ballast track could be reached.

Fig. 4 shows the track receptance for the ballast track, the (unisolated) slab track and the (isolated) floating slab track. The different flexibility of the tracks plays an important role on the load transmission from the tracks to the soil. The ballasted track presents two flexibility levels, the rail-pads and the ballast layer, while the conventional slab track only has the flexibility level provided by the rail-pads. Due to that, in the case of the ballasted track, the rail, the sleeper and the track-soil interface have similar displacements, whereas in the slab track the displacements at the rail level are much higher than the others. For a slab track, the track-soil interface displacements match up with the sleeper displacements. In a floating slab track, the insertion of the slab mat causes an increase of the displacement around the isolation frequency. In comparison with the unisolated slab track, the floating slab track presents higher rail displacements until $60 \mathrm{~Hz}$, approximately. After that, the rail has a similar response in both tracks. In a similar way, an amplification of the response of the sleeper and the track-soil interface occurs around the isolation frequency of the slab track. However, the isolated slab track presents track-soil interface displacements much lower than the unisolated track at frequencies higher than about $20 \mathrm{~Hz}$. It can be concluded that an effective control of the track-soil interface vibrations is achieved at frequencies sufficiently higher than the isolation frequency, while vibrations increase at lower frequencies. In the next section, the effectiveness of the floating slab track for a moving load is studied.

\section{Induced vibration due to HST passage}

In this section, the induced vibrations due to HST passage on ballasted and non-ballasted tracks are computed for different train speeds. The influence of quasi-static and dynamic excitation mechanisms in relation to the train speed, the soil dynamic properties, and the effect of the track stiffness on the free-field 


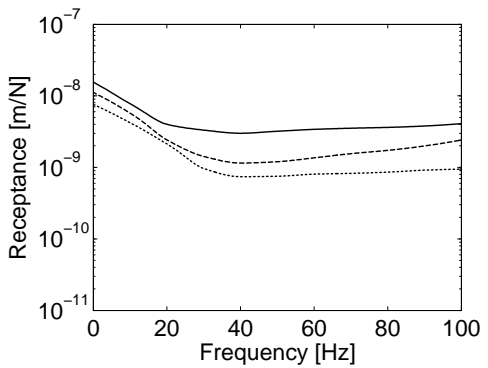

(a)

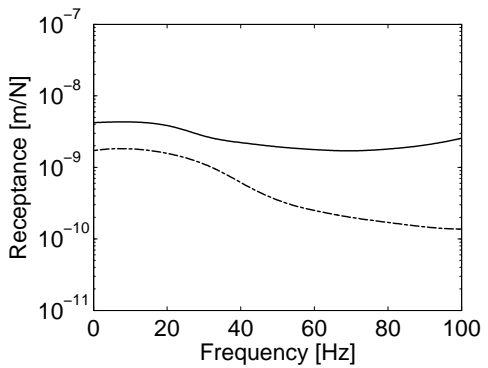

(b)

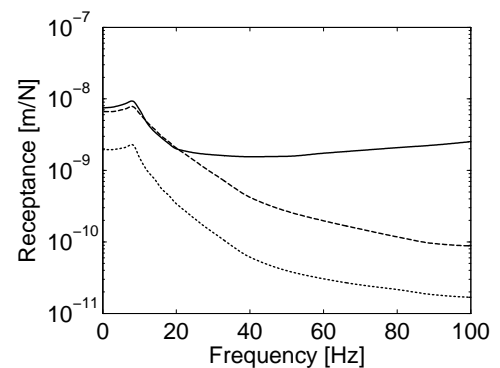

(c)

Figure 4: Receptance of the rail (solid line), the sleeper (dotted line) and the track-soil interface (dashed-dotted line) for: (a) ballast track, (b) slab track and (c) floating slab track.

response are analyzed using the discretizations shown in Fig. 3. The time step used in the time domain numerical model depends on the train speed and it allows to represent the quasi-static load and the rail and wheel irregularities. The properties of the different track systems and the soil properties are the same as in the previous section. The carriage length $L_{t}$, the distance $L_{b}$ between bogies, the axle distance $L_{a}$, the total axle mass $M_{t}$, the sprung axle mass $M_{s}$ and the unsprung axle mass $M_{u}$ of all the carriages are shown in Fig. 5 and Table 1.

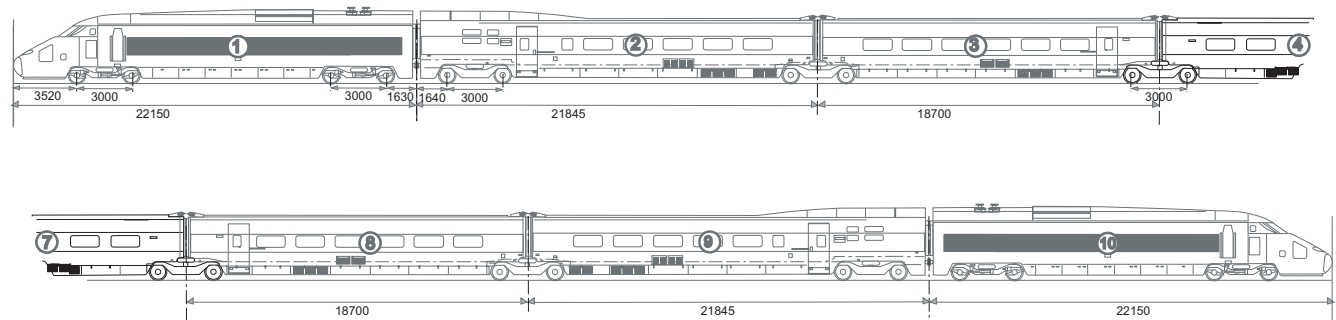

Figure 5: Configuration of the HST.

Table 1: Geometrical and mass characteristics of the HST.

\begin{tabular}{|c|c|c|c|c|c|c|c|}
\hline & No. of carriages & No. of axles & $L_{t}[\mathrm{~m}]$ & $L_{b}[\mathrm{~m}]$ & $L_{a}[\mathrm{~m}]$ & $M_{u}[\mathrm{~kg}]$ & $M_{t}[\mathrm{~kg}]$ \\
\hline Traction cars & 2 & 4 & 22.15 & 14.00 & 3.00 & 1733 & 17000 \\
\hline End carriages & 2 & 3 & 21.84 & 18.70 & 3.00 & 1830 & 14500 \\
\hline Central carriages & 6 & 2 & 18.70 & 18.70 & 3.00 & 1826 & 17000 \\
\hline
\end{tabular}


Figs. 6-8 compare the track and the free field displacements for the ballast track, the unisolated slab track and the isolated slab track due to a single axle travelling at $v=250 \mathrm{~km} / \mathrm{h}, v=280 \mathrm{~km} / \mathrm{h}$ and $v=315$ $\mathrm{km} / \mathrm{h}$, respectively. The results are shown on the same scale. Fig. 6 shows the track and soil behaviour for a train speed lower than the Rayleigh wave velocity in the soil. In this case, the vertical soil displacements are almost symmetric with respect to the moving load for the considered ballast track system. Track induced vibrations in ballasted and floating slab tracks are higher than in the slab track. The radiation of waves from the track to the soil varies with the type of track. The effect of the load is concentrated in the ballast track, but it spreads through both the slab track and the floating slab track. If the soil and track behaviours for ballasted system is compared for the three speeds (Figs. 6.(a), 7.(a) and 8.(a)), it can be observed that the symmetry of the soil motion is lost as $v$ increases due to radiation effect of the Mach waves, and the soil displacements are amplified for $v=280 \mathrm{~km} / \mathrm{h}$ (Fig. 7.(a)). That is, $v=280 \mathrm{~km} / \mathrm{h}$ is close to the critical speed of this systems. This effect is not observed in the slab tracks that remains in the same condition due to the lower flexibility of the system (Figs. 6.(b,c), 7.(b,c) and 8.(b,c)).

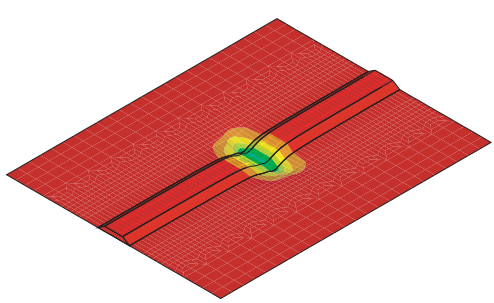

(a)

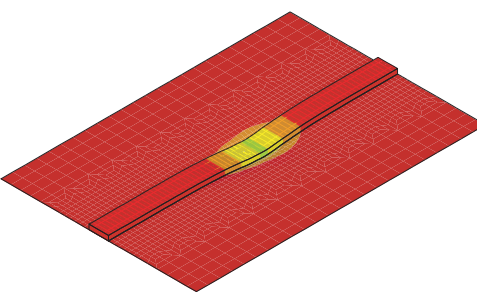

(b)

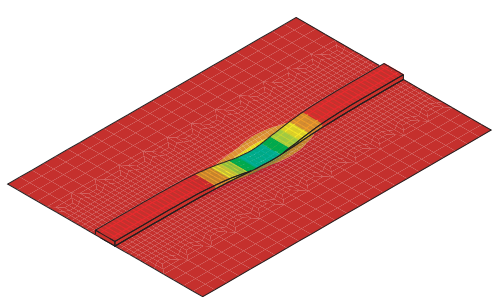

(c)

Figure 6: Track and free field displacements due to a single axle travelling at $v=250 \mathrm{~km} / \mathrm{h}$ for: (a) ballast track, (b) unisolated slab track and (c) isolated slab track.

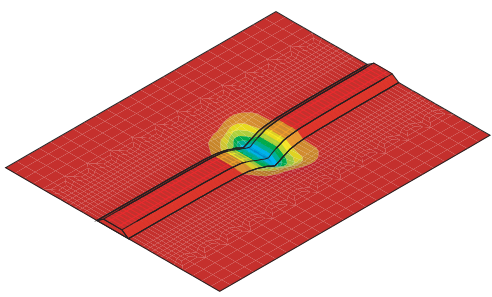

(a)

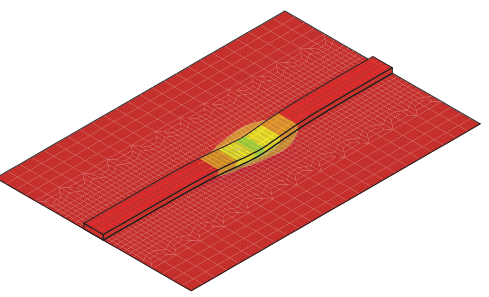

(b)

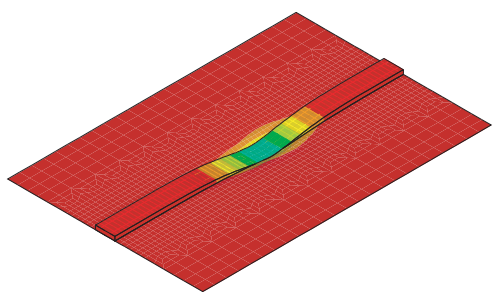

(c)

Figure 7: Track and free field displacements due to a single axle travelling at $v=280 \mathrm{~km} / \mathrm{h}$ for: (a) ballast track, (b) unisolated slab track and (c) isolated slab track.

Figs. 9, 10 and 11 show the vertical velocity time histories, frequency contents and one-third octave band spectra at the rail for train speeds $v=250 \mathrm{~km} / \mathrm{h}, v=280 \mathrm{~km} / \mathrm{h}$ and $v=315 \mathrm{~km} / \mathrm{h}$, and the three 


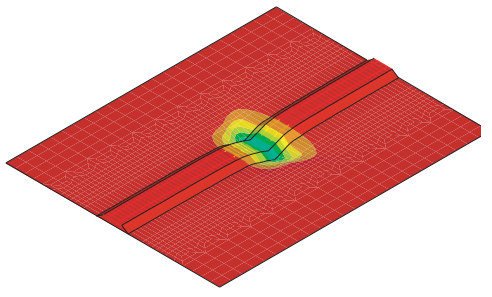

(a)

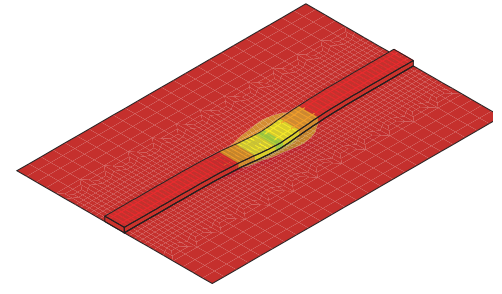

(b)

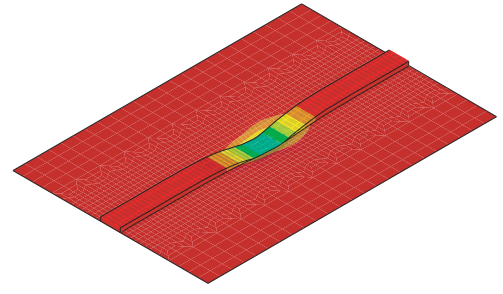

(c)

Figure 8: Track and free field displacements due to a single axle travelling at $v=315 \mathrm{~km} / \mathrm{h}$ for: (a) ballast track, (b) unisolated slab track and (c) isolated slab track.

different track systems. The quasi-static contribution (grey line) is superimposed to the total contribution (black line) in all the figures. It can be concluded that the quasi-static contribution dominates the rail response. For the ballast track (first column), an amplification in the response for a train speed $v=280$ $\mathrm{km} / \mathrm{h}$ is detected. Induced vibrations for the unisolated (second column) and isolated (third column) slab tracks increase with the train speed. If the unisolated and the isolated track systems are compared, it is concluded that rail induced vibrations increase when the resilient mat is included in the track. Peaks at the bogie passing frequency, axle passing frequency, sleeper passing frequency and related high-order harmonic frequencies produced by the quasi-static contribution can also be observed in all the frequency content plots show in Figs. 10 and 11. In the isolated slab track, peaks around the isolated frequency are amplified. Fig. 11 shows the one-third octave band spectra of the vertical velocity. Dynamic excitation is important only for frequencies higher than $50 \mathrm{~Hz}$.

Figs. 12, 13 and 14 show the vertical velocity time histories, frequency contents and one-third octave band spectra at the sleeper for train speeds $v=250 \mathrm{~km} / \mathrm{h}, v=280 \mathrm{~km} / \mathrm{h}$ and $v=315 \mathrm{~km} / \mathrm{h}$, and the three different track systems. Induced vibration at the sleeper is higher for the ballasted track than for the other considered systems. In this system, the quasi-static contribution dominates the sleeper response. For the floating slab track, the sleeper response is dominated for the frequency range close to the isolation frequency where the response is amplified. According to Fig. 14, for non-ballasted track, the dynamic contribution is noticeable around $25 \mathrm{~Hz}$.

Last, Figs. 15, 16 and 17 show the vertical velocity time histories, frequency contents and one-third octave band spectra at a point on the soil surface located at $11.8 \mathrm{~m}$ from the axis track for train speeds equal $v=250 \mathrm{~km} / \mathrm{h}, v=280 \mathrm{~km} / \mathrm{h}$ and $v=315 \mathrm{~km} / \mathrm{h}$, and the three different track systems. For the ballast track system the amplification of the velocity when the train reaches the system critical speed $v=280$ $\mathrm{km} / \mathrm{h}$ is noticeable. Then, the response of the considered soil surface point is dominated for the quasi-static excitation mechanism. However, in the non-ballasted track systems, the soil surface response is controlled by the dynamic excitation mechanism. That is, the system critical speed is not reached yet. 
(a)
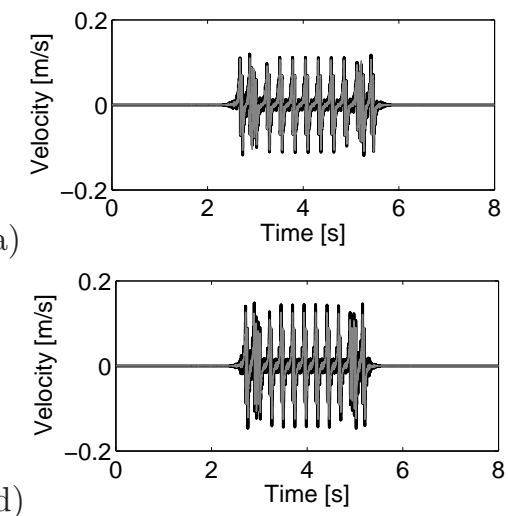

(d)

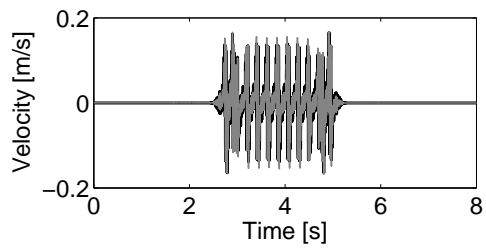

(b)
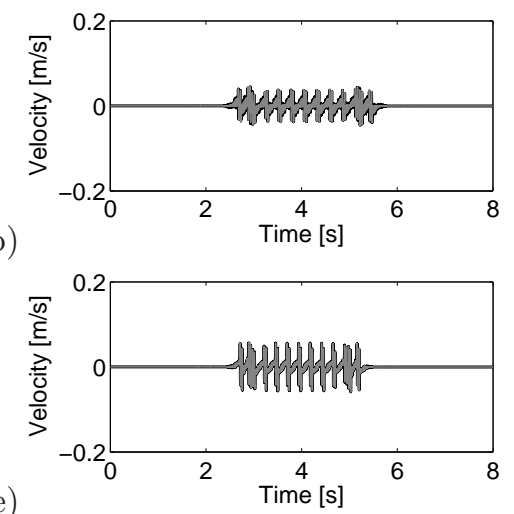

(e)

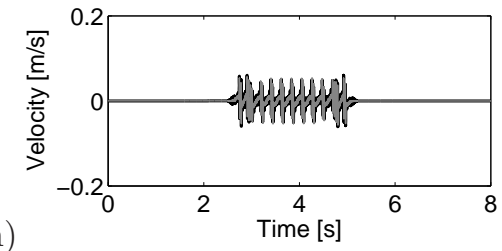

(c)
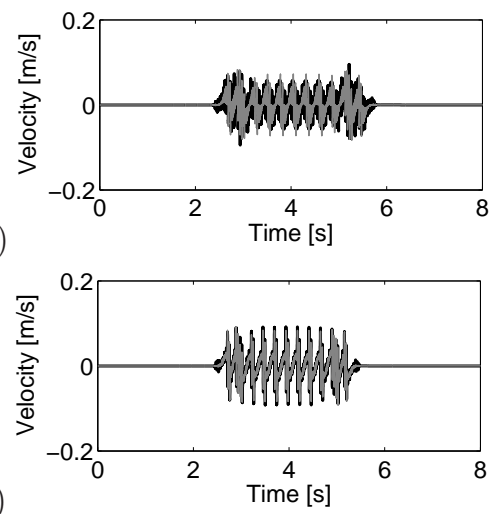

(f)

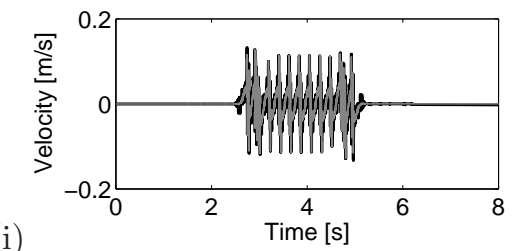

Figure 9: Time history of the vertical velocity at the rail for train speeds of $v=250 \mathrm{~km} / \mathrm{h}(\mathrm{a}-\mathrm{c}), v=280 \mathrm{~km} / \mathrm{h}(\mathrm{d}-\mathrm{f})$ and $v=315 \mathrm{~km} / \mathrm{h}(\mathrm{g}-\mathrm{i})$, travelling on ballast track (a, d, g), slab track (b, e, h) and floating slab track (c, f, i). The quasi-static contribution (grey line) is superimposed to the total contribution (black line).

(a)
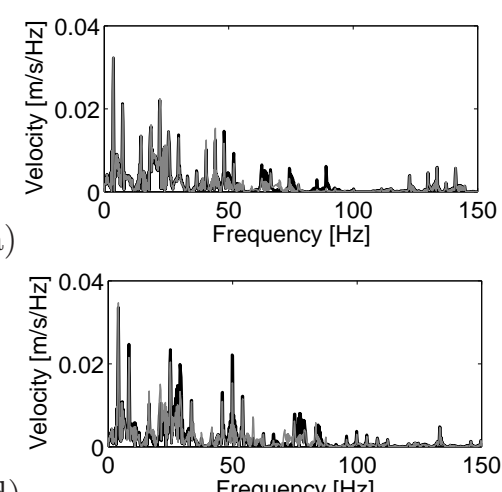

(d)

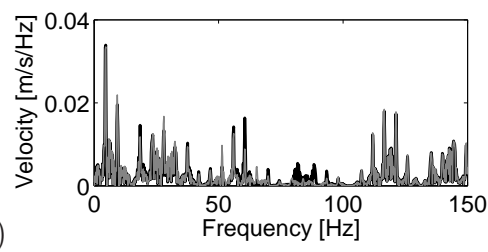

(b)
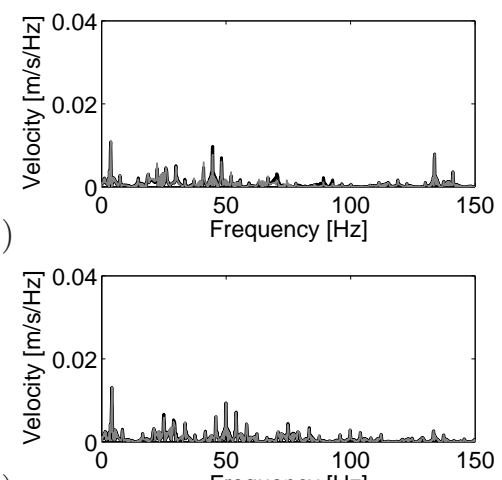

(e)

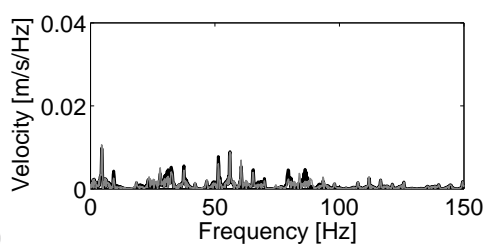

(c)
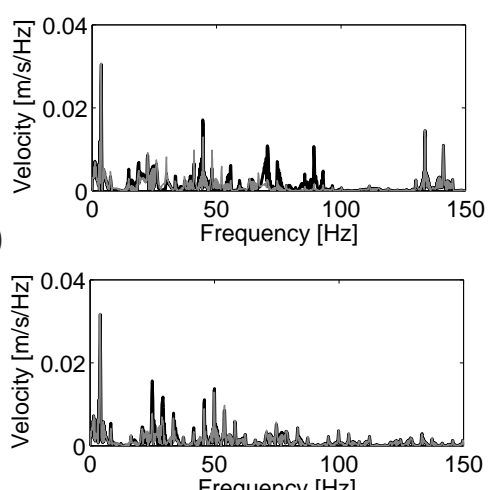

(f)

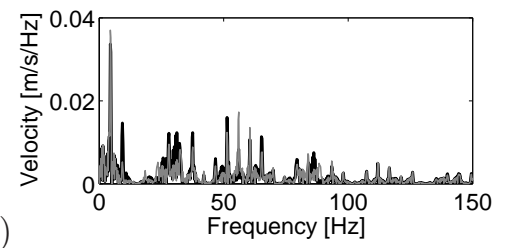

Figure 10: Frequency content of the vertical velocity at the rail for train speeds of $v=250 \mathrm{~km} / \mathrm{h}(\mathrm{a}-\mathrm{c}), v=280 \mathrm{~km} / \mathrm{h}(\mathrm{d}-\mathrm{f})$ and $v=315 \mathrm{~km} / \mathrm{h}$ (g-i), travelling on ballast track (a, d, g), slab track (b, e, h) and floating slab track (c, f, i). The quasi-static contribution (grey line) is superimposed to the total contribution (black line). 
(a)

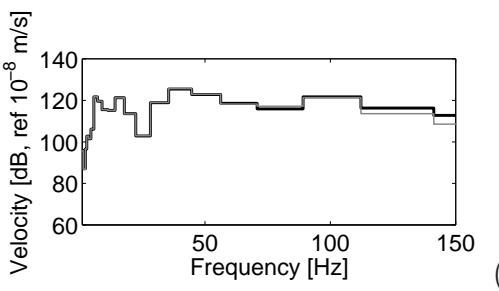

(d)
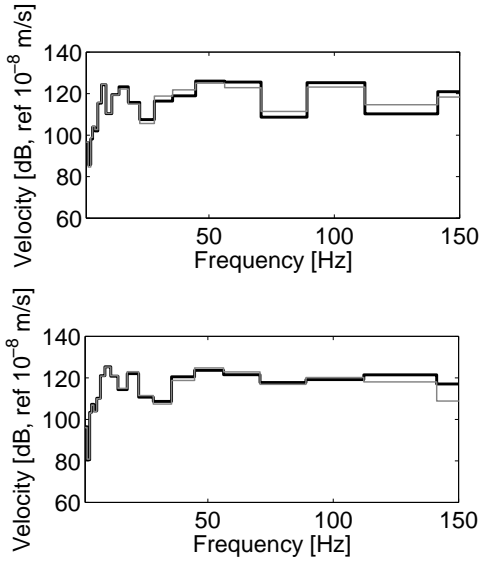

(b)

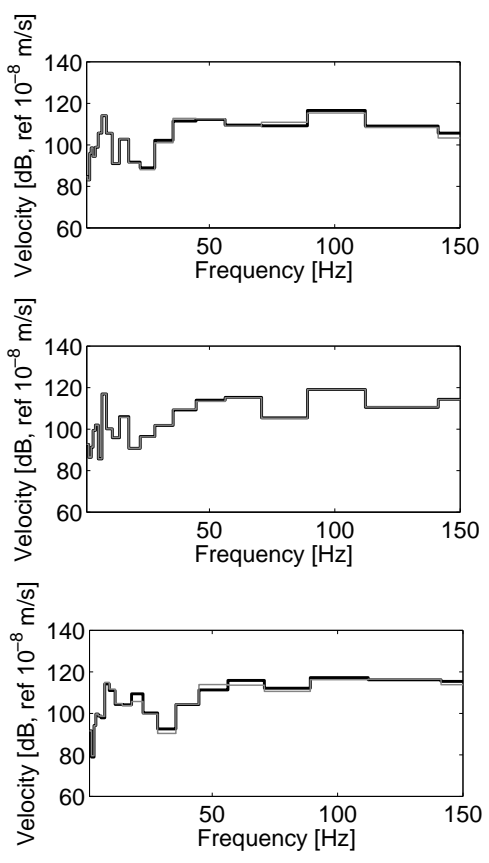

(c)

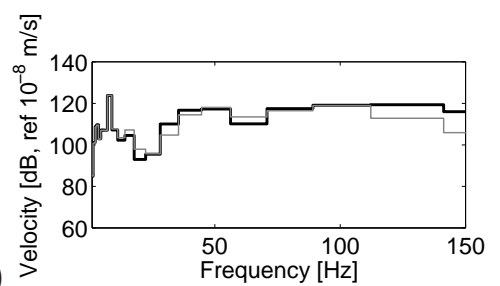

(f)

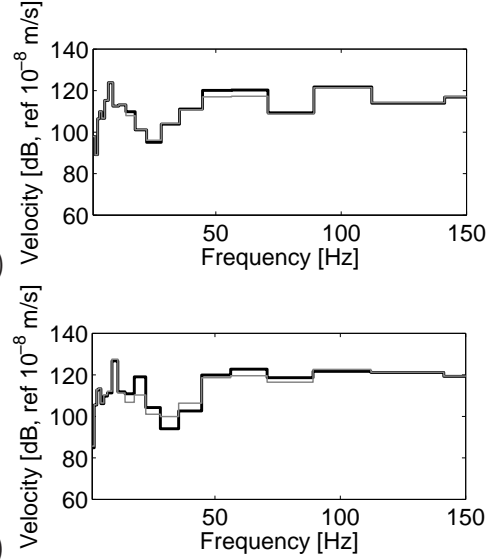

Figure 11: One-third octave band spectra of the vertical velocity at the rail for train speeds of $v=250 \mathrm{~km} / \mathrm{h}(\mathrm{a}-\mathrm{c}), v=280$ $\mathrm{km} / \mathrm{h}(\mathrm{d}-\mathrm{f})$ and $v=315 \mathrm{~km} / \mathrm{h}$ (g-i), travelling on ballast track (a, d, g), slab track (b, e, h) and floating slab track (c, f, i). The quasi-static contribution (grey line) is superimposed to the total contribution (black line).

(a)
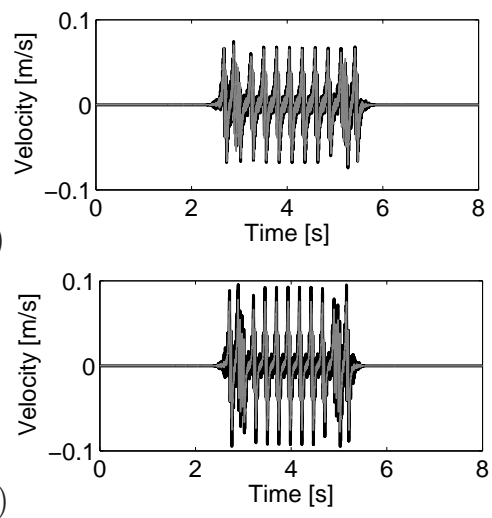

(d)

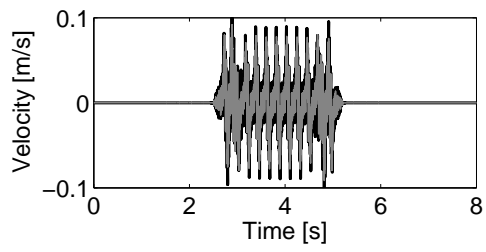

(b)

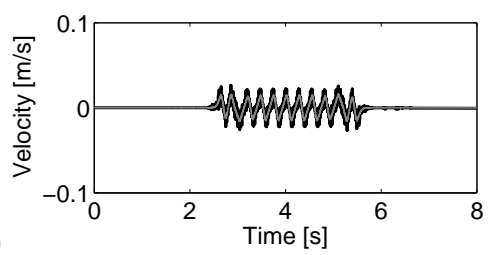

(e)

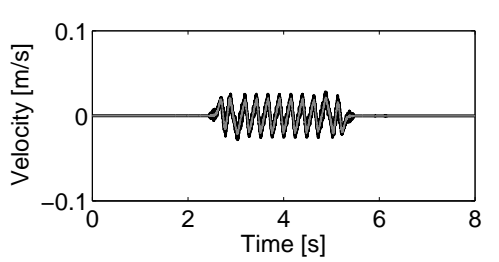

(h)

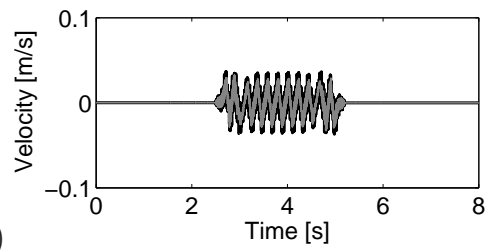

(c)
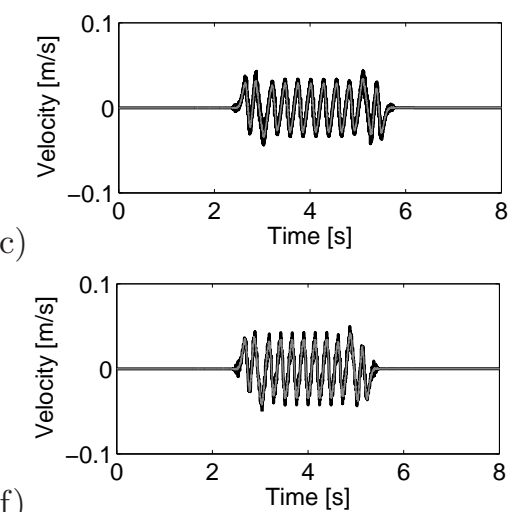

(f)

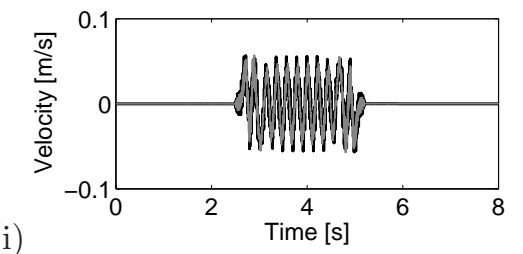

Figure 12: Time history of the vertical velocity at the sleeper for train speeds of $v=250 \mathrm{~km} / \mathrm{h}(\mathrm{a}-\mathrm{c}), v=280 \mathrm{~km} / \mathrm{h}(\mathrm{d}-\mathrm{f})$ and $v=315 \mathrm{~km} / \mathrm{h}(\mathrm{g}-\mathrm{i})$, travelling on ballast track (a, d, g), slab track (b, e, h) and floating slab track (c, f, i). The quasi-static contribution (grey line) is superimposed to the total contribution (black line). 
(a)
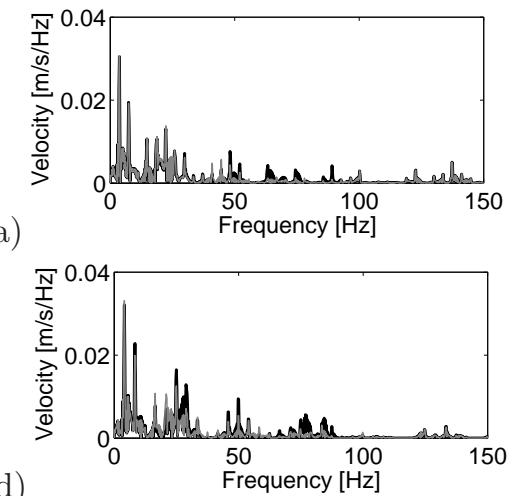

(d)

(g)

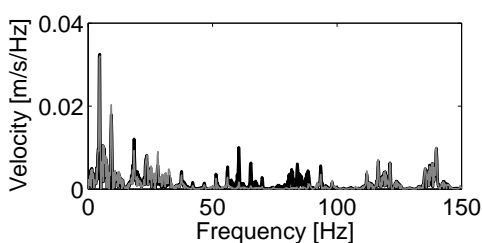

(b)
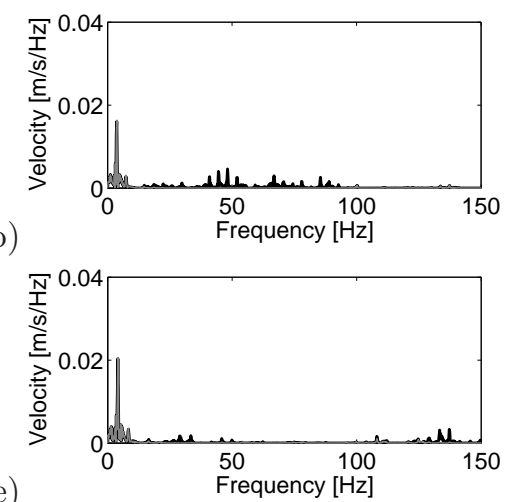

(e)

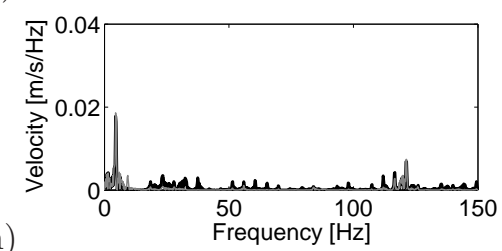

(c)
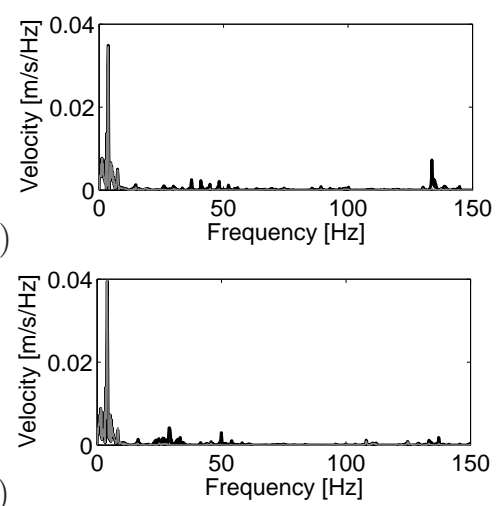

(f)

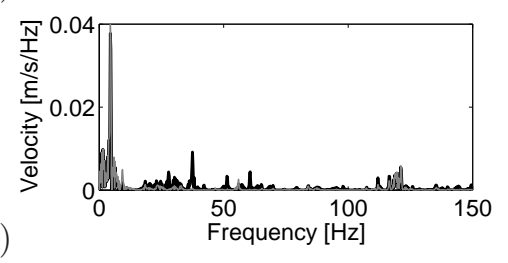

Figure 13: Frequency content of the vertical velocity at the sleeper for train speeds of $v=250 \mathrm{~km} / \mathrm{h}(\mathrm{a}-\mathrm{c}), v=280 \mathrm{~km} / \mathrm{h}(\mathrm{d}-\mathrm{f})$ and $v=315 \mathrm{~km} / \mathrm{h}(\mathrm{g}-\mathrm{i})$, travelling on ballast track (a, d, g), slab track (b, e, h) and floating slab track (c, f, i). The quasi-static contribution (grey line) is superimposed to the total contribution (black line).

(a)
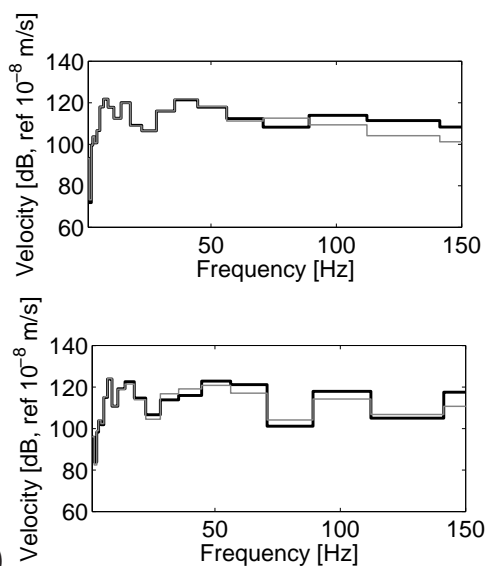

(d)

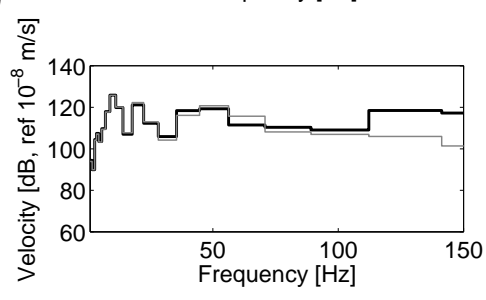

(b)

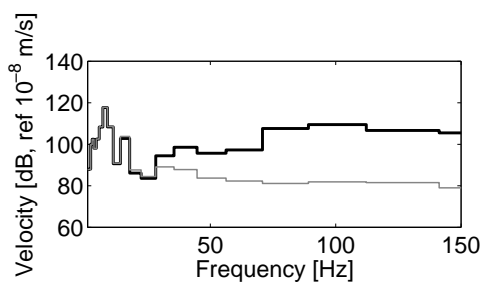

क्ल

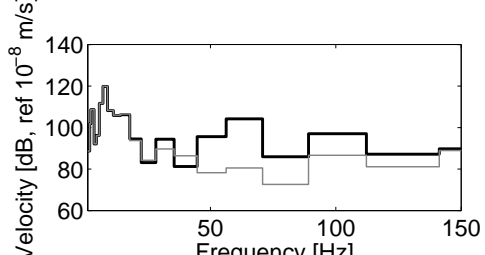

(e)

(h)

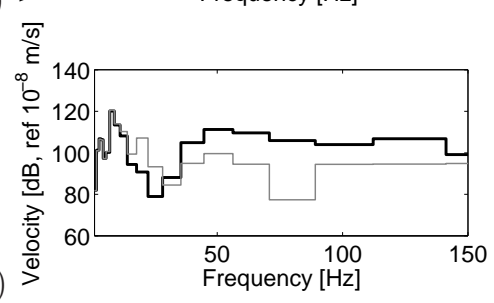

(c)

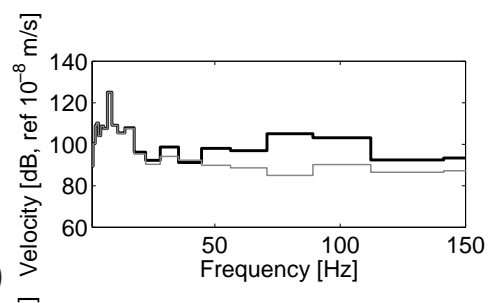

要

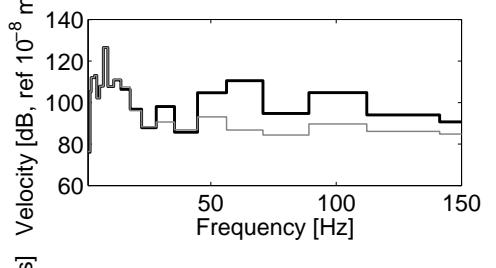

(f)

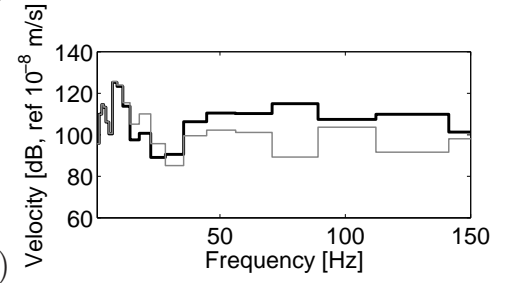

Figure 14: One-third octave band spectra of the vertical velocity at the sleeper for train speeds of $v=250 \mathrm{~km} / \mathrm{h}(\mathrm{a}-\mathrm{c}), v=280$ $\mathrm{km} / \mathrm{h}(\mathrm{d}-\mathrm{f})$ and $v=315 \mathrm{~km} / \mathrm{h}$ (g-i), travelling on ballast track (a, d, g), slab track (b, e, h) and floating slab track (c, f, i). The quasi-static contribution (grey line) is superimposed to the total contribution (black line). 

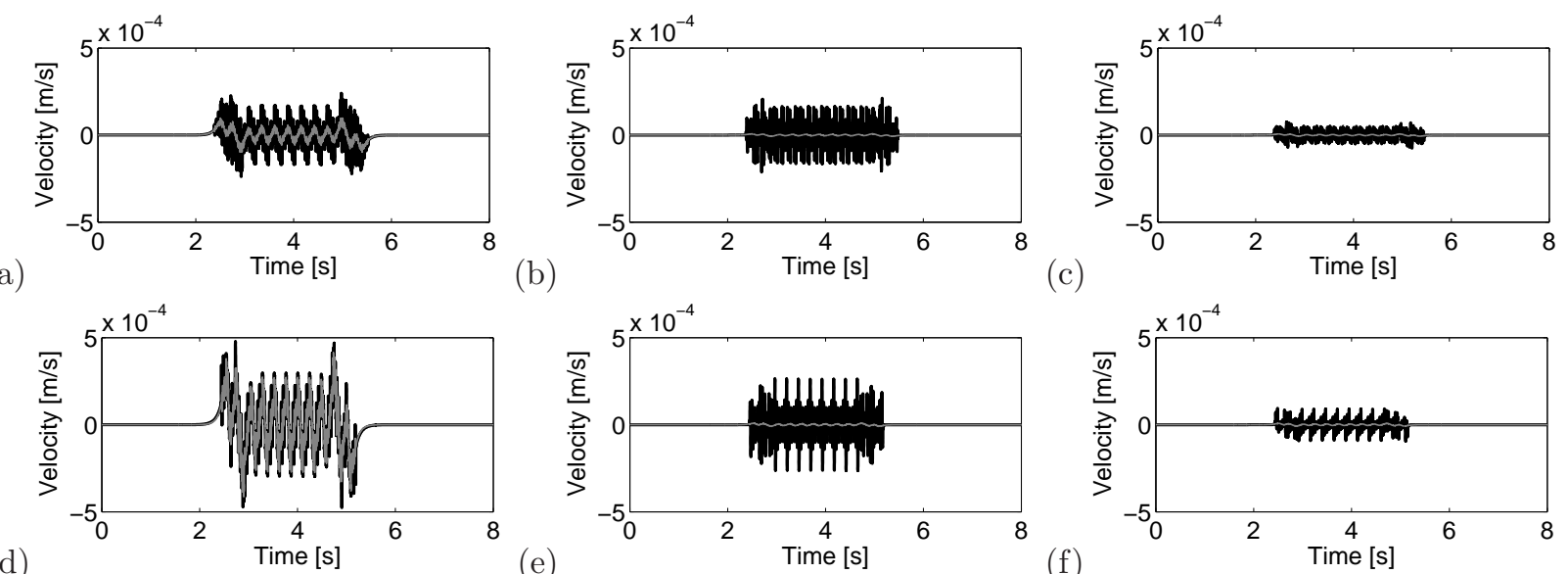

(b)

(c)
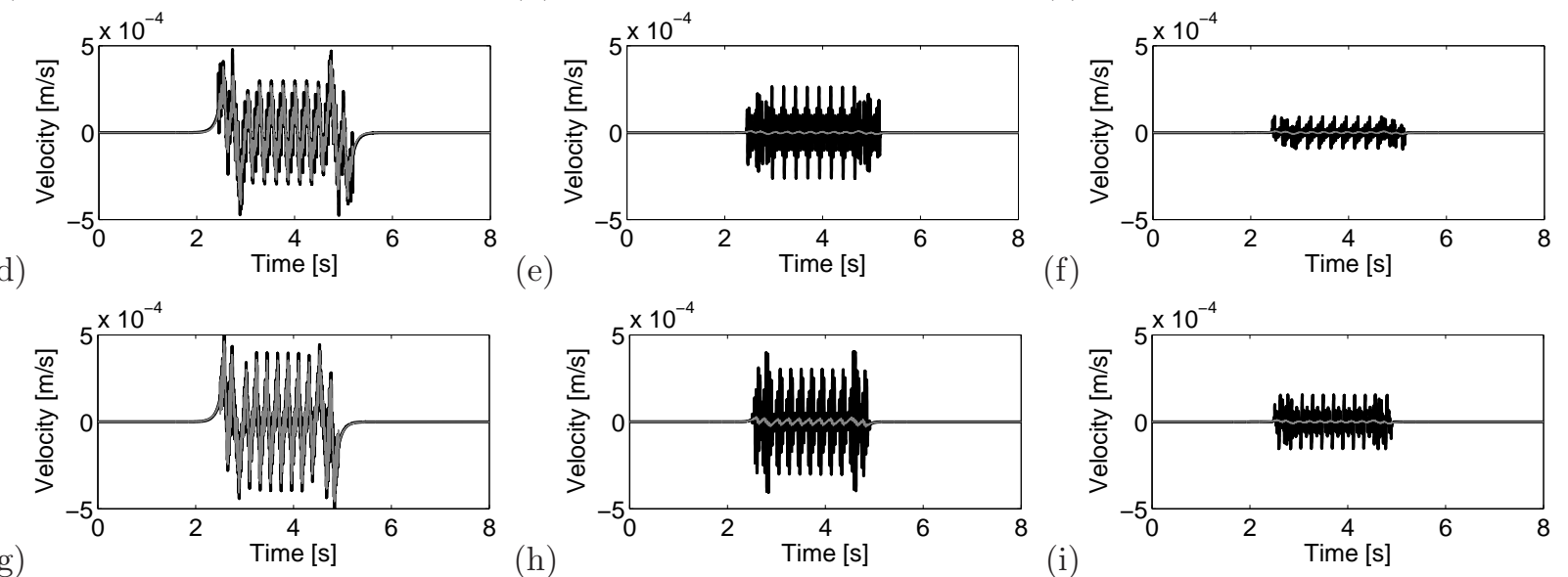

Figure 15: Time history of the vertical velocity at a point on the soil surface located at $11.8 \mathrm{~m}$ from the track axis for train speeds of $v=250 \mathrm{~km} / \mathrm{h}(\mathrm{a}-\mathrm{c}), v=280 \mathrm{~km} / \mathrm{h}(\mathrm{d}-\mathrm{f})$ and $v=315 \mathrm{~km} / \mathrm{h}$ (g-i), travelling on ballast track (a, d, g), slab track (b, $\mathrm{e}, \mathrm{h}$ ) and floating slab track (c, f, i). The quasi-static contribution (grey line) is superimposed to the total contribution (black line). 
(a)
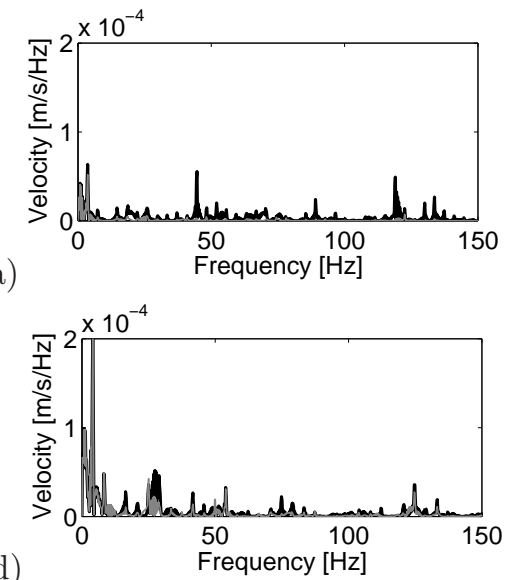

(d)

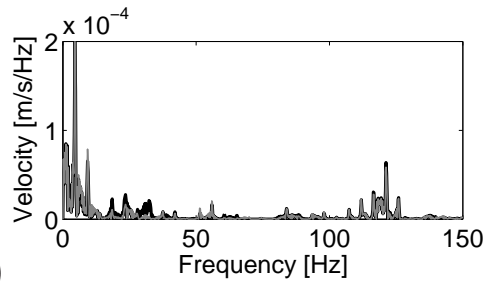

(b)
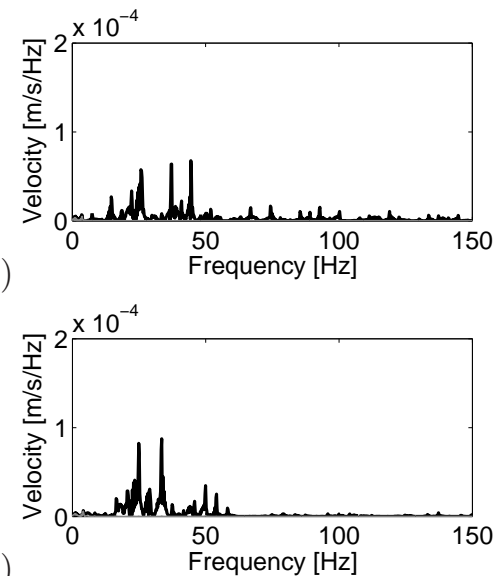

(e)

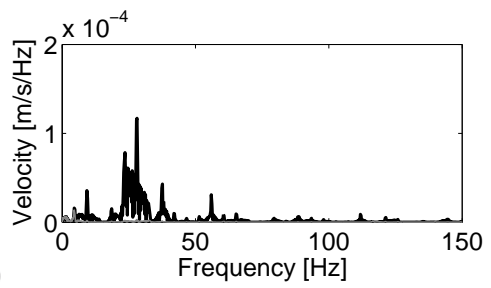

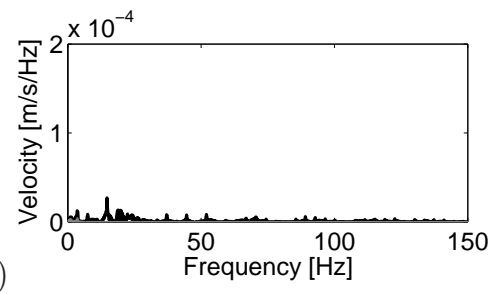

(c)

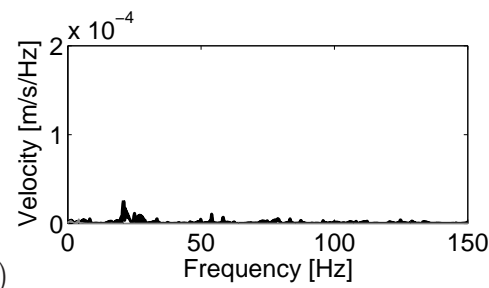

(f)

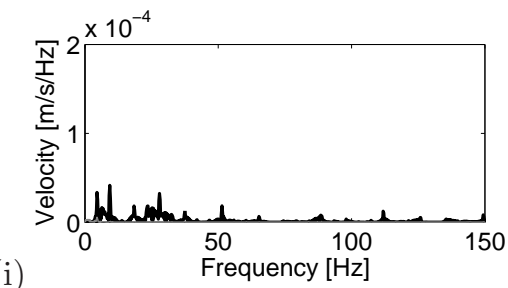

Figure 16: Frequency content of the vertical velocity at a point on the soil surface located at $11.8 \mathrm{~m}$ from the track axis for train speeds of $v=250 \mathrm{~km} / \mathrm{h}(\mathrm{a}-\mathrm{c}), v=280 \mathrm{~km} / \mathrm{h}(\mathrm{d}-\mathrm{f})$ and $v=315 \mathrm{~km} / \mathrm{h}$ (g-i), travelling on ballast track (a, d, g), slab track $(\mathrm{b}, \mathrm{e}, \mathrm{h})$ and floating slab track (c, f, i). The quasi-static contribution (grey line) is superimposed to the total contribution (black line). 
(a)

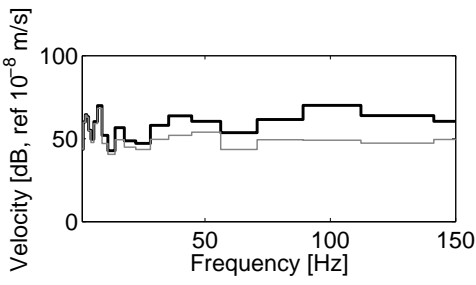

(d)

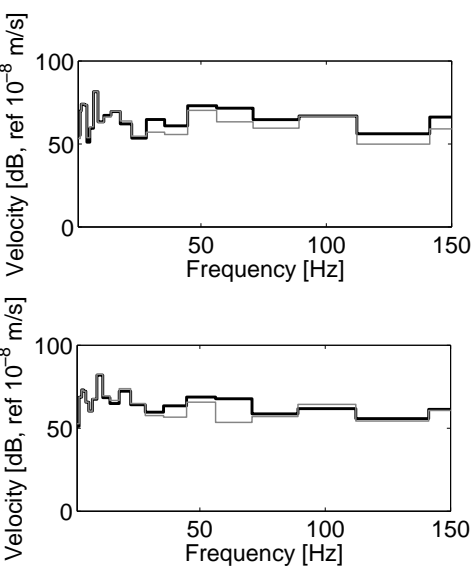

(b)
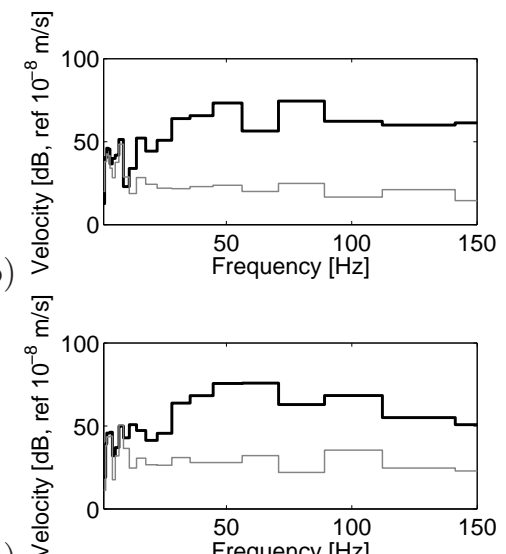

(e)

(h)

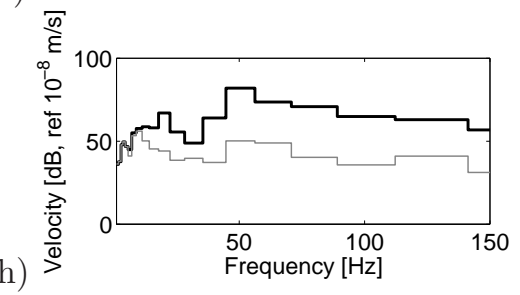

(c)

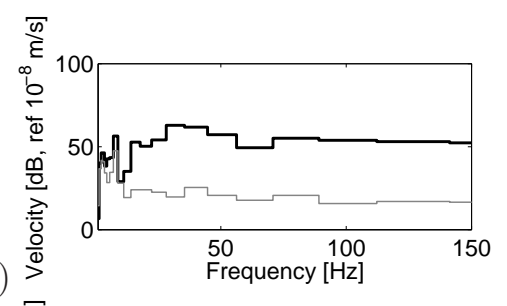

(f)

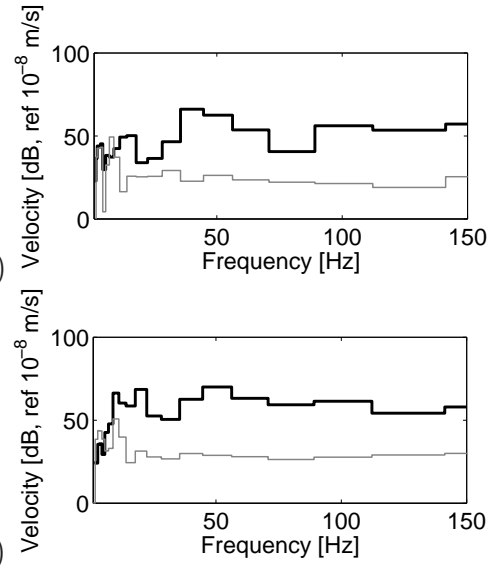

Figure 17: One-third octave band spectra of the vertical velocity at a point on the soil surface located at $11.8 \mathrm{~m}$ from the track axis for train speeds of $v=250 \mathrm{~km} / \mathrm{h}(\mathrm{a}-\mathrm{c}), v=280 \mathrm{~km} / \mathrm{h}$ (d-f) and $v=315 \mathrm{~km} / \mathrm{h}$ (g-i), travelling on ballast track (a, $\mathrm{d}, \mathrm{g}$ ), slab track (b, e, h) and floating slab track (c, f, i). The quasi-static contribution (grey line) is superimposed to the total contribution (black line). 
The concept of insertion loss in $\mathrm{dB}$ which indicates the decrease in vibration levels caused by the slab mat is used at this point. The insertion loss (IL) is defined as the ratio of the response $u^{\text {uniso }}$ of the unisolated and the response $u^{\text {iso }}$ of the isolated system:

$$
\mathrm{IL}[\mathrm{dB}]=20 \log \left(\frac{u^{\text {uniso }}}{u^{\text {iso }}}\right)
$$

Positive values of the insertion loss correspond to a smaller response of the isolated track. Fig. 18 shows the insertion loss at a point on the soil surface located at $11.8 \mathrm{~m}$ from the axis track for the considered train speeds. It can be observed that a reduction of $20 \mathrm{~dB}$ is obtained by the insertion of the resilient material. From the figure it can be concluded that the isolation effectiveness reduces as the train speed increases for frequencies higher than about $50 \mathrm{~Hz}$.

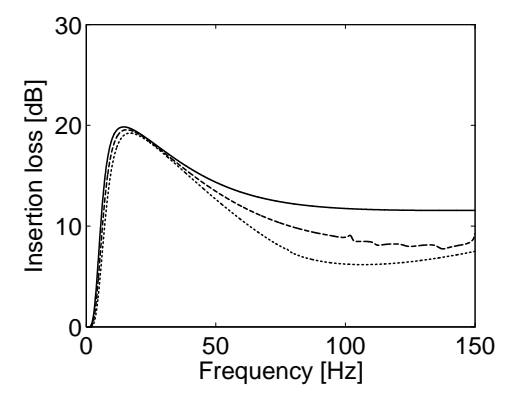

Figure 18: Insertion gain at a point on the soil surface located at $11.8 \mathrm{~m}$ from the track axis for train speeds of $v=250 \mathrm{~km} / \mathrm{h}$ (solid line), $v=280 \mathrm{~km} / \mathrm{h}$ (dashed line) and $v=315 \mathrm{~km} / \mathrm{h}$ (dotted line).

\section{Conclusions}

In this paper a general and fully coupled three dimensional multi-body-finite element-boundary element model is used to compute induced vibration at the track and the free-field by HST passage on ballast and non-ballast tracks. Both, quasi-static and dynamic excitation mechanisms are taken into account. The vehicle is modelled as a multi-body system. Tracks are modelled using finite elements and a soft soil is represented using boundary elements.

It can be concluded from the computed results that the critical speed for a ballast track is close to the Rayleigh wave velocity in the soil. Therefore, the quasi-static excitation mechanism dominates the soil response. However, for non-ballasted tracks, it is not observed that the critical system speed is reached. So, the excitation due to rail and wheel unevenness controls the soil response.

Finally, the insertion of a resilient material in the slab track for vibration reduction has been studied in a surface line on soft soil. The insertion of the slab mat led to an amplification of the response at frequencies around the isolation frequency. After that, a reduction of the response is attained. Due to that, the floating 
slab system presents vibrations higher than the slab system at the track where the response is controlled by the quasi-static contribution. However, at the soil surface far from the track vibrations are reduced up to $20 \mathrm{~dB}$; however, it is noticeable that the system reduces its effectiveness as the train speed increases.

\section{Acknowledgements}

This research is financed by the Ministerio de Educación y Ciencia of Spain under the research project BIA2007-67612-C02-02 and by the CEDEX under the research project PT-2006-024-19CCPM. The financial support is gratefully acknowledged.

\section{References}

[1] C. Esveld, Modern Railway Track, MRT Productions, Zaltbommel, 2001.

[2] International Organization for Standardization. ISO 2631-2:2000: Vibrations et chocs mécaniques - Evaluation de l'exposition des individus à des vibrations globales du corps - Partie 2: Vibrations dans les bâtimens $(1 \mathrm{~Hz}$ à $80 \mathrm{~Hz})$, 2000 .

[3] K. Adolfsson, B. Andréasson, P.-E. Bengtson, A. Bodare, C. Madshus, R. Massarch, G. Wallmark, P. Zackrisson, High speed lines on soft ground. Evaluation and analyses of measurements from the West Coast Line, Technical Report, Banverket, 1999.

[4] H.A. Dieterman, A.V. Metrikine, The equivalent stiffness of a halfspace interacting with a beam. Critical velocities of a moving load along the beam, European Journal of Mechanics, A/Solids 15 (1996) 67-90.

[5] V.V. Krylov, Generation of ground vibration boom dy high-speed trains, in: V. Krylov (Ed.), Noise and vibration from high-speed trains, Thomas Telford Publishing, London, 2001.

[6] MJMM. Steenbergen, A.V. Metrikine, The effect of the interface conditions on the dynamic response of a beam on a half-space to a moving load, European Journal of Mechanics, A/Solids 26 (2007) 33-54.

[7] H. Xia, Y.M. Cao, G. De Roeck, Theoretical modeling and characteristic analysis of moving-train induced ground vibrations, Journal of Sound and Vibration (2009), doi:10.1016/j.jsv.2009.10.007

[8] G. Lombaert, G. Degrande, B. Vanhauwere, B. Vandeborght, S. François, The control of ground-borne vibrations from railway traffic by means of continuous floating slabs, Journal of Sound and Vibration 297 (2006) 946-961.

[9] G. Degrande, D. Clouteau, R. Othman, M. Arnst, H. Chebli, R. Klein, P. Chatterjee, B. Janssens, A numerical model for ground-borne vibrations from underground railway traffic based on a periodic finite element-boundary element formulation, Journal of Sound and Vibration 293 (2006) 645-666.

[10] S. Gupta, M.F.M. Hussein, G. Degrande, H.E.M. Hunt, D. Clouteau, A comparison of two numerical models for the prediction of vibrations from underground railway traffic, Soil Dynamics and Earthquake Engineering 27 (2007) 608-624.

[11] M. Heckl, G. Hauck, R. Wettschureck, Structure-borne sound and vibration from rail traffic, Journal of Sound and Vibration 193 (1996) 175-184.

[12] V. Krylov, Generation of ground vibrations by superfast trains, Applied Acoustics 44 (1995) 149-164.

[13] G. Degrande, Free field vibrations during the passage of a high speed train: experimental results and numerical predictions, in: V. Krylov (Ed.), Noise and vibration from high-speed trains, Thomas Telford Publishing, London, 2001.

[14] P. Galvín, J. Domínguez, High-speed train-induced ground motion and interaction with structures, Journal of Sound and Vibration 307 (2007) 755-777. 
[15] X. Sheng, C.J.C. Jones, D.J. Thompson, A comparison of a theoretical model for quasi-statically and dynamically induced environmental vibration from trains with measurements, Journal of Sound and Vibration 267 (2003) 621-635.

[16] G. Lombaert, G. Degrande, J. Kogut, S. François, The experimental validation of a numerical model for the prediction of railway induced vibrations, Journal of Sound and Vibration 297 (2006) 512-535.

[17] L. Auersch, The effect of critically moving loads on the vibrations of soft soils and isolated railway tracks, Journal of Sound and Vibration 310 (2008) 587-607.

[18] G. Lombaert, G. Degrande, Ground-borne vibration due to static and dynamic axle loads of InterCity and high-speed trains, Journal of Sound and Vibration 297 (2006) 512-535.

[19] A.V. Metrikine, S.N. Verichev, J. Blauwendraad, Stability of a two-mass oscillator moving on a beam supported by a visco-elastic half-space, International Journal of Solids and Structures (2005) 1187-1207.

[20] A.V. Metrikine, K. Popp, Instability of vibrations of an oscillator moving along a beam on an elastic half-space, European Journal of Mechanics, A/Solids 18 (1999) 331-349.

[21] L. Auersch, The excitation of ground vibration by rail traffic: theory of vehicle-track-soil interaction and measurements of high-speed lines, Journal of Sound and Vibration 284 (2005) 103-132.

[22] H. Takemiya, X. Bian, Substructure simulation of inhomogeneous track and layered ground dynamic interaction under train passage, Journal of Engineering Mechanics 131 (2005) 699-711.

[23] A.V. Metrikine, K. Popp, Vibration of a periodically supported beam on an elastic half-space, European Journal of Mechanics, A/Solids 18 (1999) 679-701.

[24] X. Sheng, C.J.C. Jones, D.J. Thompson, A theoretical model for ground vibration from trains generated by vertical track irregularities, Journal of Sound and Vibration 272 (2004) 937-965.

[25] X. Sheng, C.J.C. Jones, D. J. Thompson, Prediction of ground vibration from trains using the wavenumber finite and boundary element methods, Journal of Sound and Vibration 293 (2006) 575-586.

[26] E. Kausel, J.M. Roësset, Stiffness matrices for layered soils, Bulletin of the Seismological Society of America 71 (1981) 1743-1761.

[27] A.J.B. Tadeu, E. Kausel, Green's functions for two-and-a-half-dimensional elastodynamic problems, Journal of Engineering Mechanics 126 (2000) 1093-1097.

[28] O.C. Zienkiewicz, The Finite Element Method, McGraw-Hill Company, London, 1977.

[29] D.E. Beskos, Boundary element methods in dynamic analysis, Applied Mechanics Reviews 40 (1987) 1-23.

[30] D.E. Beskos, Boundary element methods in dynamic analysis. Part II. (1986-1996), Applied Mechanics Reviews 50 (1997) 149-197.

[31] J. Domínguez, Boundary elements in dynamics, Computational Mechanics Publications and Elsevier Applied Science, Southampton, 1993.

[32] P. Galvín, J. Domínguez, Analysis of ground motion due to moving surface loads induced by high-speed trains, Engineering analysis with boundary elements 30 (2007) 931-941.

[33] P. Galvín, J. Domínguez, Experimental and Numerical Analysis of Vibrations Induced by High-Speed Trains on the Córdoba-Málaga Line, Soil Dynamics and Earthquake Engineering 29 (2009) 641-657.

[34] M. Marrero, J. Domínguez, Numerical behavior of time domain BEM for three-dimensional transient elastodynamic problems, Engineering analysis with boundary elements 27 (2002) 39-48.

[35] D.D. Barkan, Dynamics of Bases and Foundations, McGraw-Hill, New York, 1962.

[36] N.M. Newmark, A method of computation for structural dynamics, ASCE Journal of the Engineering Mechanics Division 85 (1959) 67-94.

[37] K. Knothe, S.L. Grassie, Modelling of railway track and vehicle/track interaction at high frequencies, Vehicle System Dynamics 22 (1993) 209-262. 
[38] International Organization for Standardization. ISO 8608:1995: Mechanical vibration - Road surface profiles - Reporting of measured data, 1995.

[39] D.L. Karabalis, D.E. Beskos, Dynamic response of 3D flexible foundations by time domain BEM and FEM, Soil Dynamics and Earthquake Engineering 4 (1985) 91-101.

[40] S.Y. Chang, Nonlinear error propagation analysis for explicit pseudodynamics algorithm, Journal of engineering mechanics ASCE 123 (2003) 841-850. 